\title{
Antimicrobial Activity of Leaves of Acacia Arabica against Pathogenic Organisms Compared with Control Drug
}

\author{
C.J. Chandekar* \\ Department of Microbiology, Shri Shivaji Education Society Amravati's Science College, \\ Congress Nagar, Nagpur 440 012, Maharashtra, India \\ *Corresponding author
}

\section{A B S T R A C T}

\begin{tabular}{l} 
Ke y w o r d s \\
Antimicrobial activity, \\
Acacia arabica, \\
Pathogenic organisms, \\
Control drug \\
\hline
\end{tabular}

Article Info

Accepted:

20 September 2018

Available Online:

10 October 2018
The crude extract from the leaves of Acacia Arabica traditionally used in Indian system of medicines were screened against Escherichia coli NCIM 2931, Salmonella typhi MTCC 734, Salmonella typhimurium MTCC 98, Klebsiella pneumoniae MTCC432, Proteus vulgaris NCIM2857, Proteus mirabilis MTCC425, Pseudomonas aeruginosa NCIM5029, Staphylococcus aureus MTCC 96, Staphylococcus epidermis MTCC 435, Bacillus cereus NCIM2155, Bacillus subtilis NCIM 2063 and Bacillus megaterium NCIM 2087 by using agar well diffusion method. Acacia arabica crude extract showed significant activity against Gram negative organisms. Zone of inhibition of the extract compared with the standard antibiotics.

\section{Introduction}

Plants produce a diverse range of bioactive molecules making them a rich source of different types of medicines (Stuffness and Douros, 1982). Higher plants as sources of medicinal compounds have continued to play a dominant role in the maintenance of human health care since ancient times. Over 50\% of all modern clinical drugs are of natural product origin and natural product play a vital role in modern drug development in the pharmaceutical industry (Baker et al., 1995). Plants with possible antimicrobial activity should be tested against an appropriate microbial model to confirm the activity and to ascertain the parameters associated with it.
The effects of plant extract on bacteria have been studied by a very large number of researches in different parts of the world (Ates and Erdogrul, 2003). Much work has been done on ethnomedicinal plants in India (Negi et al., 1993). Interest in a large number of traditional natural products has increased (Taylor et al., 1996). It has been suggested that aqueous and Ethanolic extract from plants used in allopathic medicine are potential sources of antiviral, Anti tumural and antimicrobial agents (Chung et al., 1995). The selection of the crude plants extract for screening programmes has the potential of being more successful in initial steps than the screening of pure compounds isolated from natural products (Kusumoto et al., 1995). 
There is continuous and urgent need to discover new antimicrobial compounds with diverse chemical structures and novel mechanisms of actions because there has been alarming increase in the incidence of new and re-emerging infectious diseases.

\section{Materials and Methods}

Selection of medicinal plant for this study:

\section{Acacia Arabica}

Family: Leguminosae

Parts used: Leaf

Traditional uses: Acacia species are commonly known as 'Babool' in India and traditionally used for its medicinal properties for the treatment of skin, sexual, stomach and tooth problems

Identification and Preservation of Plant materials:

Fresh plant leaves were collected from the Nagpur area of India. The taxonomic identities of this plant were determined by the expertise of the Post Graduate Department of Botany of Rashtrasant Tukadoji Maharaj Nagpur University, Nagpur. Specimen was labeled, numbered and noted with date of collection, the locality, their medicinal uses and their approximate dosages of administration were recorded. Plant leaves were washed with $70 \%$ alcohol and then rinsed with sterilized distilled water, air dried and stored in airtight bottles at $4^{\circ} \mathrm{C}$ for further use.

\section{Preparation of crude extracts (Fresh juice)}

Acacia arabica plant leaves were collected from around Nagpur region in the month of August-September. Leaves were cleaned under running potable water and cut into pieces and grounded in pestle and mortar (made up of dolerite stone) till homogenized mass was obtained. Homogenized mass was squeezed in 400 mesh nylon cloth (pore size 37 micron) to obtain crude extract. Crude extract was kept in sterilized glass bottle. All crude extract were prepared fresh and used within 2 hours for further testing.

\section{Crude extraction}

Aqueous extraction: Ten grams of dried powder was extracted in $100 \mathrm{ml}$ distilled water for $6 \mathrm{~h}$ at slow heat. Every $2 \mathrm{~h}$, it was filtered through 8 layers of muslin cloth and centrifuged at $5000 \mathrm{~g}$ for $15 \mathrm{~min}$. The supernatant was collected. This process was repeated twice and after $6 \mathrm{~h}$, the supernatant was concentrated to make the final volume one-fourth of the original volume (Shahidi Bonjar, 2004). It was then autoclaved at $121^{\circ} \mathrm{C}$ and $15 \mathrm{lbs}$ pressure and then stored at $4^{\circ} \mathrm{C}$.

\section{Solvent extraction}

Ten grams of dried powder was extracted with $100 \mathrm{ml}$ of each solvent (acetone, chloroform, methanol and petroleum ether) and flasks were kept on a rotary shaker at 190-220 rpm for 24h. Thereafter, it was filtered through 8 layers of muslin cloth and centrifuged at 5000 $\mathrm{g}$ for $15 \mathrm{~min}$. The supernatant was collected and the solvent was evaporated to make the final volume one-fourth of the original volume (Shahidi Bonjar, 2004). It was stored at $4^{\circ} \mathrm{C}$ in airtight bottles for further studies.

\section{Bacterial cultures}

The microbial strains are identified strains and were procured from the National Chemical Laboratory (NCL), Pune, India. The studied bacterial strains were Bacillus cereus NCIM2155, Bacillus subtilis NCIM2063, Bacillus megaterium NCIM2087, Escherichia coli NCIM2931, Proteus vulgaris NCIM2857 and Pseudomonas aeruginosa NCIM5029. Staphylococcus aureus MTCC96, 
Staphylococcus epidermis MTCC 435, Salmonella typhi MTCC 734, Salmonella typhimurium MTCC 98, Klebsiella pneumoniae MTCC432, Proteus mirabilis MTCC425, these strains were procured from Institute of Microbial Technology (IMTECH), Chandigarh, India. They were sub-cultured on nutrient agar for every 15 days and maintained on nutrient agar slants at $4^{0} \mathrm{C}$, fresh inoculums were taken for test.

\section{Media}

Hi -Sensitivity test broth (M 486) and Hisensitivity test agar (M 485) were procured from Hi-media Mumbai, India. The media were prepared according to the instructions given.

Screening for the antimicrobial potential of the plant leaves extracts

The antimicrobial activity of different solvent extracts was evaluated by agar well diffusion (Perez C, et al., 1990, Nair and Chanda, 2005 and Parekh, J. et al., 2007) using Hisensitivity test agar (M 485).

Preparation of inoculum - A loopful of culture was inoculated from the stock slant culture in $5 \mathrm{ml}$ of Hi-sensitivity test broth and broth was incubated at $35 \pm 0.5^{\circ} \mathrm{C}$ in incubator for $18-20$ hrs. After incubation a loopful of actively growing culture was inoculated into $10 \mathrm{ml}$ of Hi-sensitivity broth. Broth was incubated at $35 \pm 0.5^{\circ} \mathrm{C}$ for $6-8$ hours. This culture was used for the inoculation of Hi-sensitivity test agar plates.

\section{Preparation of Hi-sensitivity test agar medium}

Hi-sensitivity test agar medium was prepared as per instructions of manufacturer. Required amount of agar medium was melted and $25 \mathrm{ml}$ of molten medium was distributed in test tubes (25x150 mm). Medium was autoclaved at 15 lb. for 20 min. After autoclaving, medium was maintained at $45-50^{\circ} \mathrm{C}$ in constant temperature water bath.

\section{Inoculation of medium with test organism}

$0.5 \mathrm{ml}$ of 6-8 hours old test organism is transferred to petridish of $100 \mathrm{~mm}$ size (Sterilized in oven at $180^{\circ} \mathrm{C}$ for $1 \mathrm{hr}$.) using sterile micropipette. Hi-sensitivity test agar medium maintained at $45-50^{\circ} \mathrm{C}$ was poured and mixed properly to ensure uniform distribution of organism with medium. Seeded plates are allowed to set at room temperature.

\section{Preparation of agar well for fresh leaves juice}

$10 \mathrm{~mm}$ borer was used to prepare wells in agar. Four wells per plate at four equidistant corners were made. A $100 \mu l$ crude extract (fresh leaves juice) was transferred by micropipette per well.

Plates were immediately kept at $4^{0} \mathrm{C}$ in refrigerator for $1 \mathrm{hr}$. for the good diffusion of extract and then shifted to $35 \pm 0.5^{\circ} \mathrm{C}$ in incubator (Venkatesan et al., 2009). Zone of inhibition was measured after $24 \mathrm{hrs}$ of incubation by zone scale.

Preparation of agar wells for different solvent extracts

$5 \mathrm{~mm}$ borer was used to prepare wells in agar. Four wells per plate at four equidistant corners were made.

A 50 ul solvent extract was transferred by micropipette per well. Plates were immediately kept at $4^{0} \mathrm{C}$ in refrigerator for 1 hr. and then shifted to $35^{\circ} \mathrm{C}+0.5^{\circ} \mathrm{C}$ in incubator. Zone of inhibition was measured after $24 \mathrm{~h}$ of incubation. 


\section{Antibacterial activity of different solvent extracts of leaves of Acacia arabica (AA), zone of inhibition in millimetre (mm)}

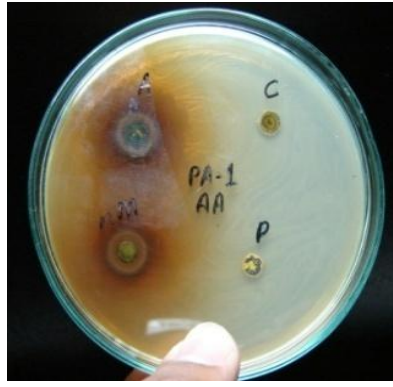

Figure-- 1

Activity against Pseudomonas aeruginosa Acetone extract (A)

Chloroform extract (C)

Methanol extract (M) $-12 \mathrm{~mm}$

Petroleum ether extract $(\mathrm{P})$

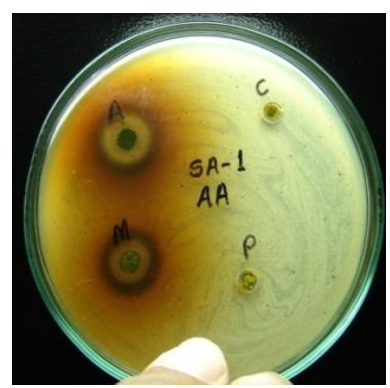

Figure-3

Activity against Staphylococcus aureus Acetone extract (A)-20 mm

Chloroform extract (C)

Methanol extract (M)-18 mm

Petroleum ether extract $(\mathrm{P})$

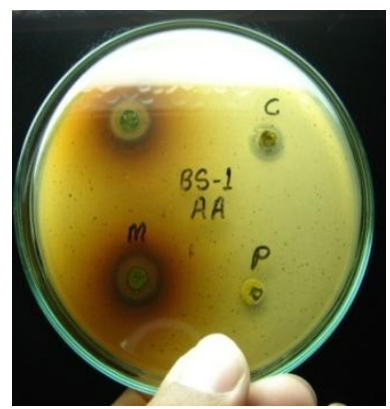

Figure-5

Activity against Bacillus subtilis Acetone extract (A)-16mm

Chloroform extract (C)-11 mm

Methanol extract (M) $-14 \mathrm{~mm}$

Petroleum ether extract $(\mathrm{P})$

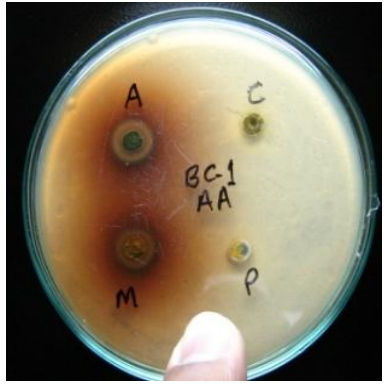

Figure--2

Activity against Bacillus cereus Acetone extract (A) $-13 \mathrm{~mm}$ Chloroform extract (C) Methanol extract (M)-13 mm Petroleum ether extract $(\mathrm{P})$

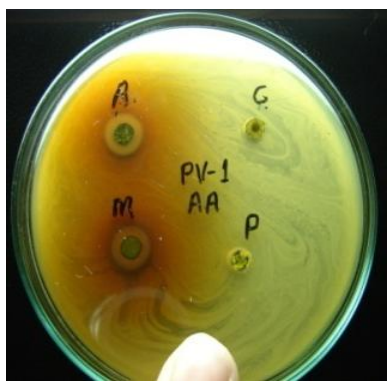

Figure--4

Activity against Proteus vulgaris Acetone extract (A)-12 mm Chloroform extract (C) Methanol extract (M)-13 mm Petroleum ether extract $(\mathrm{P})$

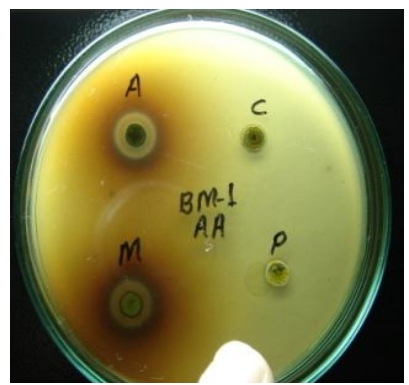

Figure--6

Activity against Bacillus megaterium Acetone extract (A)-13 mm Chloroform extract (C)

Methanol extract (M)-13 mm Petroleum ether extract $(\mathrm{P})$ 
Table.1 Results of antimicrobial activities of fresh leaves juice and solvent extracts of Acacia arabica leaves and compared with standard antibiotics

Sr.No.Microorganisms Z Zone of inhibition in millimeter

Leaves extracts $\quad$ Standard antibiotics

FJ WE AE CE ME PE $\quad \mathrm{Am}^{30} \mathrm{Cf}^{30} \mathrm{Co}^{25} \quad \mathrm{G}^{50} \mathrm{~T}^{30}$

\begin{tabular}{|c|c|c|c|c|c|c|c|c|c|c|c|}
\hline 1. Escherichia coli & --- & --- & --- & --- & --- & --- & 32 & 29 & 24 & 17 & 22 \\
\hline 2. Proteus vulgaris & 12 & --- & 12 & --- & 13 & --- & --- & 23 & 31 & 20 & 24 \\
\hline 3. Pseudomonas aureginosa & --- & --- & -- & --- & 12 & --- & 14 & 36 & --- & 34 & 22 \\
\hline 4. Staphylococcus aureus & 20 & 12 & 20 & --- & 18 & --- & 31 & 23 & 20 & 16 & 17 \\
\hline 5. Bacillus cereus & 23 & --- & 13 & --- & 13 & --- & 15 & 27 & --- & 23 & 24 \\
\hline 6. Bacillus subtilis & 14 & --- & 16 & 11 & 14 & --- & 31 & 50 & 36 & 40 & 32 \\
\hline 7. Bacillus megaterium & 13 & --- & 13 & --- & 13 & --- & 29 & 46 & 24 & 23 & 33 \\
\hline
\end{tabular}

Key: FJ—Fresh juice of leaves; WE—Water extract; AE-Acetone extract; ME-Methanol extract; CE-Chloroform Extract; PE-Petroleumether Extract; $\mathrm{Am}^{30}$--Amoxycilin; $\mathrm{Cf}^{30}$-Ciprofloxacin; $\mathrm{Co}^{25}$-Cotrimaxazole; $\mathrm{G}^{50}$-Gentamicin; Tetracycline--T ${ }^{30}$; --- Negative.

For each bacterial strain, controls were maintained in which pure solvents were used instead of the extract.

The control zones were subtracted from the test zones and the resulting zone diameter is obtained.

\section{Results and Discussion}

The extracts prepared from Acacia arabica leaves using different solvents showed varying degree of antimicrobial activity against organisms selected for the study. Among the extracts prepared using different solvents, methanol extract was found to be effective against all the organisms except Escherichia coli, While acetone extract and fresh juice was found to be effective against all the selected organisms except Pseudomonas aeruginosa and Escherichia coli, while Water extract and Chloroform Extract showed inhabitance only against Staphylococcus aureus and Bacillus subtilis respectively, petroleum ether was found ineffective against selected strains (Table 1). 
Other workers also found similar results in the above discussed extracts (Deen and Sadiq, 2002; Kavitha et al., 2013) (Rubina et al., 2015).

\section{Acknowledgement}

Post Graduate Department of Botany of Rashtrasant Tukadoji Maharaj Nagpur University, Nagpur greatly acknowledged for their support for determination of taxonomic identities of selected species.

\section{References}

Ates DA and Erdogrul OT (2003). Antimicrobial activities of various medicinal and commercial plant extract. Turk J Biol 27: 157-162.

Baker JT, Barris RP and Carte B (1995). Natural product drug discovery: New perspective on international collaboration. J. Nat Prod 58: 13251357.

Bandow JE, Brotz H, Leichert LIO, Labischinski H and Hecker M (2003). Proteomic approach to understanding antibiotic action. Antimicro. Agents. Chemotherap 47: 948-955.

Chung TH, Kim JC (1995). Investigation of Korean plant extracts for potential phytotherapeutic agents against B-virus Hepatitis. Phytotherapy Res 9: 429-434.

Deen YY, Sadiq NM (2002). Antimicrobial properties and phytochemical constituents of leaves of African mistletoe (Tapinanthus dodoneifolius (DC) Danser) (Loranthaceae): An ethnomedicinal plant of Hausaland. Northern Nig. J. Ethnopharmacol., 83: 235240.

Kavitha PA, Kumar P, Murthy TPN, Gopinath SM (2013). Methanolic extract of Acacia nilotica and antibacterial activity against Hospital isolates of Bengaluru district. Inter. J. Latest Res. Sci. Technol., 2(1): 522524

Kusumoto IT, Nakabayash $\mathrm{T}$ and Kida $\mathrm{H}$ (1995). Screening of various plant extract used in ayurvedic medicine for inhibitory effects on human immunodeficiency virus type 1 (HIV-1) protease. Phytotherapy Res 9: 180-184.

Nair R, Chanda S (2005). Antibacterial activity of Punica granatum in different solvents. Ind. J. Pharm. Sci. 67: 239243.

Negi KS, Tiwari JK and Gaur RD (1993). Notes on ethnobatony of five districts of Garhwal Himalaya, Uttar Pradesh, India. Ethnobotany 5: 73-81.

Parekh J and Chanda S (2007). In vitro antimicrobial activity and phytochemical analysis of some Indian medicinal plants. Turk J. Biol.31: 53-58.

Perez C, Paul M and Bazerque P (1990). Antibiotic assay by agar well diffusion method. Acta Bio. Med. Exp. 15: 113115.

Rubina L, Ebenezer J and Akshi G (2015). Antibacterial Activity of Acacia arabica (Bark) Extract against selected Multi Drug Resistant Pathogenic Bacteria Int.J.Curr.Microbiol.App.Sci Special Issue-1: 213-222

Shahidi Bonjar GH (2004). Evaluation of antimicrobial properties of Iranian medicinal plants against Micrococcus luteus, Serratia marcescens, Klebsiella pneumoniae and Bordetell bronchiseptica. Asian J. Plant Sci. 3: 82-86.

Stuffness M and Douros J (1982). Current status of the NCL plant and animal product program. J. Nat Prod 45: 1-14.

Taylor RSC, Manandhar NP and Hudson JB (1996). Antiviral activities of Nepalese medicinal plants. J. Ethnopharmacol 52: 157-163.

Tumane PM, Wadher BJ, Khan Aqueel, Gomashe AV and Ingle AB (2000). 
Antimicrobial activity of plant extracts. J. Microb. World. 2(2) pp47-55.

Venkatesan D, Karrunakaran CM, Selva Kumar S and Palani Swamy PT (2009). Identification of Phytochemical
Constituents of Aegle marmelos Responsible for Antimicrobial Activity against Selected Pathogenic Organisms. Ethnobotanical Leaflets. 13: 1362-72.

\section{How to cite this article:}

Chandekar, C.J. 2018. Antimicrobial Activity of Leaves of Acacia Arabica against Pathogenic Organisms Compared with Control Drug. Int.J.Curr.Microbiol.App.Sci. 7(10): 2851-2857. doi: https://doi.org/10.20546/ijcmas.2018.710.332 